\title{
Characterization of Bimetallic Castings with an Austenitic Working Surface Layer and an Unalloyed Cast Steel Base
}

\author{
Tomasz Wrobel
}

\author{
(Submitted September 20, 2013; in revised form March 6, 2014; published online March 25, 2014)
}

\begin{abstract}
The paper presents the technology of bimetallic castings based on the founding method of layer coating directly in the cast process of the so-called method of mold cavity preparation. The prepared castings consist of two fundamental parts, i.e., the base and the working surface layer. The base part of the bimetallic casting is typical foundry material, i.e., unalloyed cast steel, whereas the working layer is a plate of austenitic alloy steel sort $\mathrm{X} 2 \mathrm{CrNi} 18-9$. The quality of the joint between the base part and the working layer was evaluated on the basis of ultrasonic non-destructive testing and structure examinations containing metallographic macro- and microscopic studies with the use of a light microscope (LOM) with microhardness measurements and a scanning electron microscope (SEM) with microanalysis of the chemical composition (energy dispersive spectroscopy-EDS). On the basis of the obtained results it was confirmed that the decisive phenomena needed to create a permanent joint between the two components of the bimetallic casting are carbon and heat transport in the direction from the high-carbon and hot base material which was poured into the mold in the form of liquid metal to the low-carbon and cold material of the working layer which was placed in the mold cavity in the form of a monolithic insert.
\end{abstract}

Keywords bimetallic casting, casting, cast steel, joining, stainless steels

\section{Introduction}

In the engineering industry, there has been a noticeable, growing demand for castings with special properties such as abrasive wear resistance or corrosion resistance at room or elevated temperature. The components of this type are often produced entirely from expensive materials based on $\mathrm{Ni}, \mathrm{Co}$, $\mathrm{Ti}$, or other elements - despite the fact that in many cases the requirements for highly usable properties affect only the working surface layer of the casting, especially if the wear of an element leads to its destruction by exceeding the desired main dimension decrease.

Therefore, the technology of bimetallic castings is gaining in importance, particularly when the criterion for highly usable properties concerns only the working surface layer and the rest of the casting is only the base part which is not exposed to the direct influence of factors causing abrasive or corrosion wear. This technology constitutes the most economical way of enriching the surface of the castings as it allows for production of layered elements directly in the cast process. Therefore, this technology can be significant competition for commonly used technologies of surfacing by welding and thermal spraying, because in addition to its economic advantages it does not

Tomasz Wróbel, Department of Foundry, Silesian University of Technology, Towarowa 7, 44-100 Gliwice, Poland. Contact e-mail: tomasz.wrobel@polsl.pl. allow cracks to develop in the heat affected zone, which arises as a result of making the layer by using the welding method.

In general, the technology of bimetallic castings containing a working layer and a base part is carried out based on two fundamental methods, i.e., the liquid-liquid (Ref 1-3) and liquid-solid (Ref 4-17) configuration. An example of the former is a technology in which two independent gating systems are made that guarantee two-stage filling of the sand mold cavity. According to this manufacturing method, the bimetallic elements of the hammer (Ref 1) or ball (Ref 2) mills are cast in material configurations of the chromium cast iron working layer with a low-carbon cast steel base. Whereas the basis technology of bimetallic castings in the liquid-solid configuration is the so-called method of mold cavity preparation. In this manufacturing method, the element that enriches the surface of the casting is placed in the mold in the form of a granular (Ref 4-7) or monolithic (Ref 7-15) insert directly before the molten metal is poured. With the use of granular inserts the bimetallic castings were made in a material configuration working surface layer from $\mathrm{Fe}-\mathrm{Cr}-\mathrm{C}$ (Ref 5, 6) and Fe-Cr-C-Mo (Ref 4) or Ni-Cr-Fe-C (Ref 7) alloys with an unalloyed cast steel base. This type of bimetallic casting is characterized by a hard working surface layer that is resistant to abrasive wear, which is a decisive factor about its applicability in the mining industry. An example of technology using the monolithic insert are bimetallic castings in a configuration which comprises hard and resistant to abrasive wear chromium cast iron connected with a weldable low-carbon steel plate (Ref $8,11)$. However, a significant economic limitation of this manufacturing method is the need to preheat the steel plate (monolithic insert) placed in the mold. This treatment is carried out by two-stage mold pouring with liquid cast iron. In the first stage, the mold cavity beneath the steel plate is filled with liquid metal in order to preheat the insert. Formed in this way the layer of cast iron after cleaning is separated from the 
casting. In the second stage, the mold cavity over the steel plate is filled, in which the liquid metal forms a layer connecting with the plate and creating a bimetallic casting. Moreover, in the literature there are data about bimetallic castings made on the basis of monolithic inserts from gray cast iron dipped into a liquid hypoeutectic Al-Si alloy (Ref 16) or low-carbon steel dipping into liquid white cast iron (Ref 17).

However, the technologies of bimetallic castings presented in the available literature have large limitations, e.g., a decrease in the economic process because of the necessity of pouring two different alloys (Ref 1-3) and a decrease in the yield as a result of the necessity of applying insert preheating (Ref 8, 10 15 ) and complicating the cast process by applying two gating systems (Ref $1-3,8,11)$. Therefore, the utilitarian aim of the paper is to describe a technology of bimetallic castings in a material configuration of austenitic steel-unalloyed cast steel based on the liquid-solid method using a non-preheated monolithic insert. In the presented technology, preheating of the monolithic insert which makes it easier to form a permanent joint between the working layer and the base part and also increases the production cost as well as makes it difficult to place the steel plate in the mold cavity was replaced by application of an activator covering the contact surface between both of the materials used.

\section{Experimental Procedure}

Bimetallic castings which consisted of two fundamental parts, i.e., a base and working surface layer, were made for the study. The base part of the bimetallic casting was a typical foundry material, i.e., unalloyed cast steel, whereas the working layer was a plate of austenitic alloy steel sort X2CrNi 18-9.

Test bimetallic castings $125 \times 105 \times 45 \mathrm{~mm}$ in dimension were made in sand molds with no preheating plates of alloy steel $\mathrm{X} 2 \mathrm{CrNi} 18-9$ were placed which were then poured over with liquid unalloyed cast steel with a carbon concentration in a range of from about 0.20 to about $0.60 \mathrm{wt} \%$ in a pouring temperature of 1550,1600 , and $1650{ }^{\circ} \mathrm{C}$. The preparation methods of greensand with bentonite molds are presented in Fig. 1.

The pouring temperature was measured by using a thermocouple Pt-PtRh10 directly before the mold was poured and the carbon concentration of the cast steel base part was measured

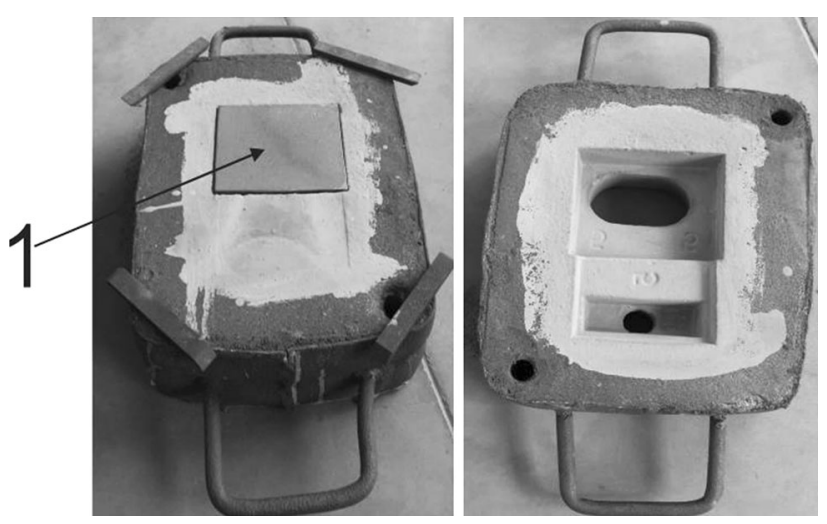

Fig. 1 View of the bottom part (left) and upper part (right) of a sand mold with a monolithic insert (1) placed in its cavity by using a LECO CS-125 analyzer. The rest of the chemical composition elements were measured with a LECO GDS500A emission spectrometer. The basic experimental plan included 16 test castings. On the basis of the results of previous studies (Ref 18), steel plates with a thickness of $5 \mathrm{~mm}$ were used whose surfaces stayed in direct contact with the liquid metal and were covered by an activator in the form of boron and sodium compounds, i.e., an aqueous solution of $\mathrm{Na}_{2} \mathrm{~B}_{4} \mathrm{O}_{7}+$ $\mathrm{B}_{2} \mathrm{O}_{3}$. These compounds promote the formation of a permanent joint between both materials of layered casting by purification of the contact surface of the oxide layer, protection against the formation of a new oxide layer and also by a decrease in the wetting angle on the insert - the liquid metal boundary. The ratio of thickness obtained in this way between the base and the working part is about $8: 1$ at a solidification module of casting that was $11.45 \mathrm{~mm}$.

The quality of the joint in the bimetallic castings was evaluated on the basis of ultrasonic non-destructive testing performed by using a DIO 562 flaw detector by STARMANS ELEKTRONICS. Then metallographic macro- and microscopic examinations were carried out. Metallographic samples were etched in reagent Mi19Fe containing $3 \mathrm{~g}$ of ferric chloride, $10 \mathrm{~cm}^{3}$ hydrochloric acid and $90 \mathrm{~cm}^{3}$ ethanol, and electrolytic polishing and etching were done in reagent A2 according to (Ref 19) with the use of LectroPol-5 STRUERS. A light microscope (LOM) NIKON and scanning electron microscope (SEM) INSPECT F were used in research on the structure with microanalysis of the chemical composition (EDS). Moreover, measurements of microhardness were done using Future-Tech FM 700 (HV0,01).

Therefore, the scientific aim of the paper was to assess the quality of the joint between the base part and the working layer depending on the pouring temperature and carbon concentration in the cast steel.

\section{Results and Discussion}

The chemical composition of material used on the working layer (steel $\mathrm{X} 2 \mathrm{CrNi} 18-9$ ) and the base part (unalloyed cast steel) of the bimetallic castings is presented in Tables 1 and 2 .

Non-destructive ultrasonic testing showed that in none of the 16 test castings in the basic experimental plan did a permanent joint occur on the whole contact surface between the working layer and the base part. The largest surface of the permanent joint for which the bottom echo was larger than the echo of the transition zone (head placed on the side of the plate) was obtained at a pouring temperature of $1650{ }^{\circ} \mathrm{C}$ and a concentration of carbon in cast steel that was equal to $0.60 \mathrm{wt} . \%$. This surface was equal to $80 \%$ of the whole contact surface of both materials. In other cases a permanent joint was obtained between the alloy steel and unalloyed cast steel on a surface that was less than $80 \%$ (Fig. 2). Moreover, it was confirmed that applying a pouring temperature of $1550{ }^{\circ} \mathrm{C}$, irrespective of the carbon concentration in cast steel, does not allow to obtain any kind of joint between the working layer and the base part in the bimetallic casting.

These results were confirmed by a macroscopic visual quality assessment made on selected sections of the test bimetallic castings (Fig. 3). Moreover, in some cases it was found that in places where on the basis of non-destructive ultrasonic testing the lack of a joint had been confirmed, in 
Table 1 Chemical composition of the alloy steel X2CrNi 18-9 working layer of a bimetallic casting

\begin{tabular}{lcccccccc}
\hline \multicolumn{2}{l}{ Elements content, wt.\% } & \multicolumn{1}{l}{} & & & & \\
\hline $\mathbf{C}$ & $\mathbf{C r}$ & $\mathbf{N i}$ & $\mathbf{S i}$ & $\mathbf{M n}$ & $\mathbf{M o}$ & $\mathbf{P}$ & $\mathbf{S}$ & $\mathbf{F e}$ \\
\hline 0.030 & 19.200 & 9.800 & 0.900 & 1.450 & 0.200 & 0.030 & 0.002 & Rest \\
\hline
\end{tabular}

Table 2 Chemical composition of the unalloyed cast steel base part of a bimetallic casting with deviations containing all melts

\begin{tabular}{|c|c|c|c|c|c|c|c|c|c|c|c|}
\hline \multicolumn{12}{|c|}{ Elements content, wt. $\%$} \\
\hline $\mathbf{C}$ & Mn & $\mathrm{Si}$ & $\mathbf{C r}$ & $\mathbf{N i}$ & Mo & $\mathbf{C u}$ & Al & Co & $\mathbf{P}$ & $\mathbf{S}$ & $\mathbf{F e}$ \\
\hline According to Fig. 2 & $\begin{array}{r}0.40 \pm \\
0.020\end{array}$ & $\begin{array}{r}0.30 \pm \\
0.060\end{array}$ & $\begin{array}{r}0.13 \pm \\
0.020\end{array}$ & $\begin{array}{r}0.10 \pm \\
0.010\end{array}$ & $\begin{array}{r}0.04 \pm \\
0.005\end{array}$ & $\begin{array}{r}0.26 \pm \\
0.030\end{array}$ & $\begin{array}{r}0.01 \pm \\
0.070\end{array}$ & $\begin{array}{r}0.02 \pm \\
0.010\end{array}$ & $\begin{array}{r}0.01 \pm \\
0.002\end{array}$ & $\begin{array}{r}0.04 \pm \\
0.006\end{array}$ & Rest \\
\hline
\end{tabular}

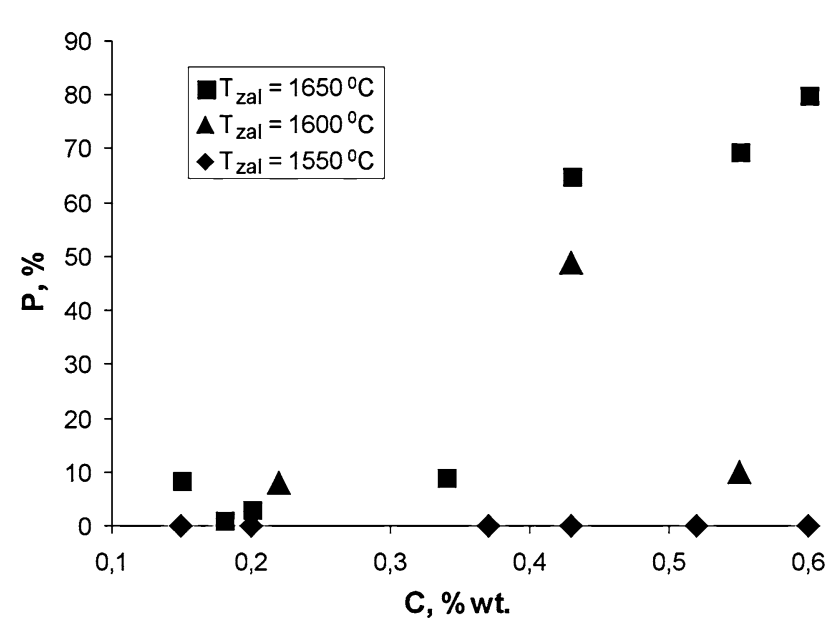

Fig. 2 Influence of the pouring temperature $\left(T_{\text {zal }}\right)$ and the carbon concentration in unalloyed cast steel $(\mathrm{C})$ on surface $(\mathrm{P})$ at which a permanent joint between alloy steel $\mathrm{X} 2 \mathrm{CrNi} 18-9$ plate and unalloyed cast steel in a bimetallic casting at module $11.45 \mathrm{~mm}$ was obtained

reality partial joints were present, which was characterized by the presence of the so-called "bimetallic connecting bridges." The presence of these so-called "bimetallic connecting bridges" also provided stability of the joint between the working and base part of bimetal in conditions of a small working load. A more detailed description of the so-called "bimetallic connecting bridges" is shown in Ref 20.

However, it was affirmed that with an increase in the pouring temperature and the carbon concentration in the material of the base part of layered casting the surface on which the permanent joint was obtained between both bimetal parts increases. Moreover, according to the data presented above, the materials configuration of a bimetallic casting consisting of chromium-nickel alloy steel and hypoeutectoid unalloyed cast steel, due to an insufficiently large difference in the carbon concentration between the jointed components despite the use of a high pouring temperature, does not guarantee that a technologically useful bimetallic casting will be obtained because it is not possible to obtain a permanent

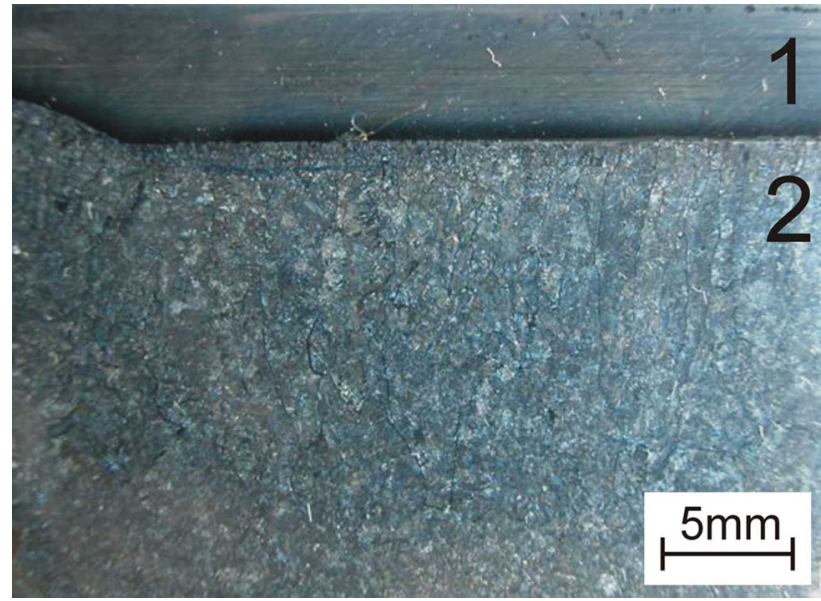

Fig. 3 Example transverse section of the bimetallic casting: 1 -working layer in the form of alloy steel $\mathrm{X} 2 \mathrm{CrNi} 18-9$ plate, 2 - base part of unalloyed cast steel at a carbon concentration equal to $0.60 \mathrm{wt} . \%$ and a pouring temperature of $1650{ }^{\circ} \mathrm{C}$

joint between the working layer and the base part on the whole contact surface.

However, in areas in which the joint between the austenitic alloy steel and ferritic-pearlitic unalloyed cast steel was obtained it was confirmed that it is durable and has a diffusion character.

A decisive factor is carbon diffusion in the direction from cast steel to the steel plate. A proximate result of this diffusion is the creation of a pearlitic transition zone $(\delta)$ with a hardness of $230 \mu \mathrm{HV}$ (Fig. 4, 5) and a thickness that is dependent on the carbon concentration in the base part (Fig. 6, 7).

Moreover, the result of the diffusion phenomenon is a decarbonising of the cast steel in the near boundary area and, in consequence, the creation in this zone of a ferritic microstructure with a small amount of pearlite, a considerably smaller amount than in the rest of the base part of the casting (Fig. 4, $8)$. This phenomenon is also seen in a linear microanalysis of the chemical composition that was carried out in the area of the joint between both materials, i.e. there is a decrease in the carbon concentration directly before the pearlitic transition zone $(\delta)$ (Fig. 9). 

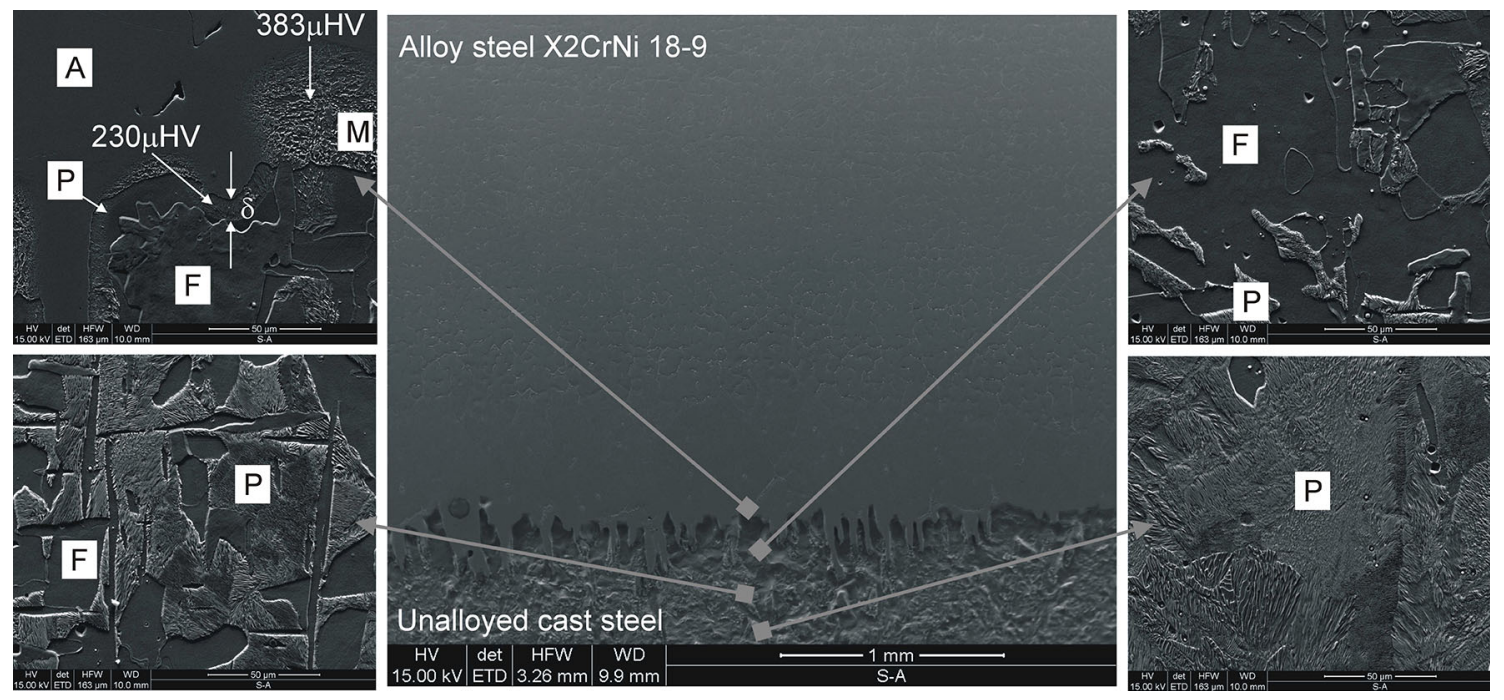

Fig. 4 Shape of the microstructure of a bimetallic casting in a configuration of the working layer in the form of an alloy steel X2CrNi 18-9 plate and the base part from unalloyed cast steel: A austenite, F ferrite, M martensite, and P pearlite, SEM, etching A2

Additionally, the near boundary area of the plate of alloy steel sort $\mathrm{X} 2 \mathrm{CrNi} 18-9$ is carbonized by the cast steel and, as a result, in this zone a microstructure of martensite with a hardness of about $380 \mu \mathrm{HV}$ is obtained (Fig. 4, 5, 10).

Besides carbonizing of the near boundary area of austenitic steel, the creation of martensite is promoted by cooling from the high temperature the plate has been heated to, and whose source is the liquid cast steel that was poured into the mold.

For a pouring temperature of $1650{ }^{\circ} \mathrm{C}$ of cast steel, the contact temperature $T_{\mathrm{s}}$ on the boundary of liquid metal-steel plate is fixed on the basis of formula (Ref 21):

$T_{\mathrm{s}}=\frac{\sqrt{\lambda_{\mathrm{n}} \cdot c_{\mathrm{n}} \cdot \rho_{\mathrm{n}}} \cdot T_{\mathrm{n}}+\sqrt{\lambda_{\mathrm{r}} \cdot c_{\mathrm{r}} \cdot \rho_{\mathrm{r}}} \cdot T_{\mathrm{r}}}{\sqrt{\lambda_{\mathrm{n}} \cdot c_{\mathrm{n}} \cdot \rho_{\mathrm{n}}}+\sqrt{\lambda_{\mathrm{r}} \cdot c_{\mathrm{r}} \cdot \rho_{\mathrm{r}}}}$

where $\lambda_{\mathrm{n}}, \lambda_{\mathrm{r}}$ coefficient of thermal conductivity, suitable for liquid cast steel (the base part of bimetallic casting) and the steel plate (working layer of bimetallic casting), W/(m K); $c_{\mathrm{n}}$, $c_{\mathrm{r}}$ specific heat, suitable for liquid cast steel (base part of bimetallic casting) and the steel plate (working layer of bimetallic casting), $\mathrm{J} /(\mathrm{kg} \mathrm{K}) ; \rho_{\mathrm{n}}, \rho_{\mathrm{r}}$ mass density, suitable for the liquid cast steel (base part of bimetallic casting) and the steel plate (working layer of bimetallic casting), $\mathrm{kg} / \mathrm{m}^{3} ; T_{\mathrm{n}}$ temperature of the liquid cast steel (base part of bimetallic casting), ${ }^{\circ} \mathrm{C}$; $T_{\mathrm{r}}$ temperature of the steel plate (working layer of bimetallic casting), ${ }^{\circ} \mathrm{C}$, is about $1100{ }^{\circ} \mathrm{C}$.

Moreover, it was confirmed that the pouring temperature has an influence on the degree of nonlinearity of boundary between the working layer and the base part, which determines the high strength of the joint between both materials in the bimetallic casting. In particular, it increases the nonlinearity of boundary as a result of an increase in the pouring temperature of cast steel (Fig. 11).

Therefore, it was confirmed that both the carbon concentration and the pouring temperature of cast steel strongly influence the quality of the joint between the working layer and the base part of the bimetallic casting, and in consequence their qualitative and quantitative influence on the microstructure and shape of the transition zones on the austenitic steel-ferritic-pearlitic cast steel boundary.

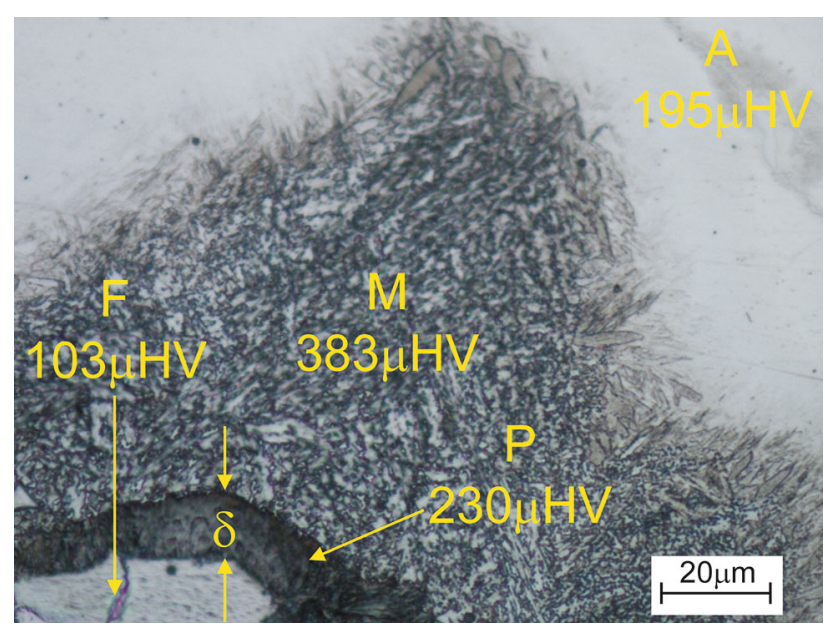

Fig. 5 Microstructure of the joint area between alloy steel $\mathrm{X} 2 \mathrm{CrNi}$ 18-9 (upper part) and unalloyed cast steel (bottom part) in a bimetallic casting: A austenite, $\mathrm{F}$ ferrite, $\mathrm{M}$ martensite, and $\mathrm{P}$ pearlite, LOM, etching Mi19Fe

\section{Conclusions}

Based on the conducted examinations the following conclusions have been formulated:

1. Achievement of the necessary, permanent joint between the plate of alloy steel sort $\mathrm{X} 2 \mathrm{CrNi} 18-9$ and unalloyed cast steel in a bimetallic casting at the assumed solidification module and a properly prepared contact surface by application of the presented activator demands simultaneously two conditions, i.e., a suitable, high pouring temperature of liquid cast steel poured into the mold in which a $5 \mathrm{~mm}$ thick plate of austenitic alloy steel is placed and also a suitable difference in the carbon concentration between both joined materials. Fulfilling only one of these conditions results in obtaining a defective casting which has no application characteristics. 

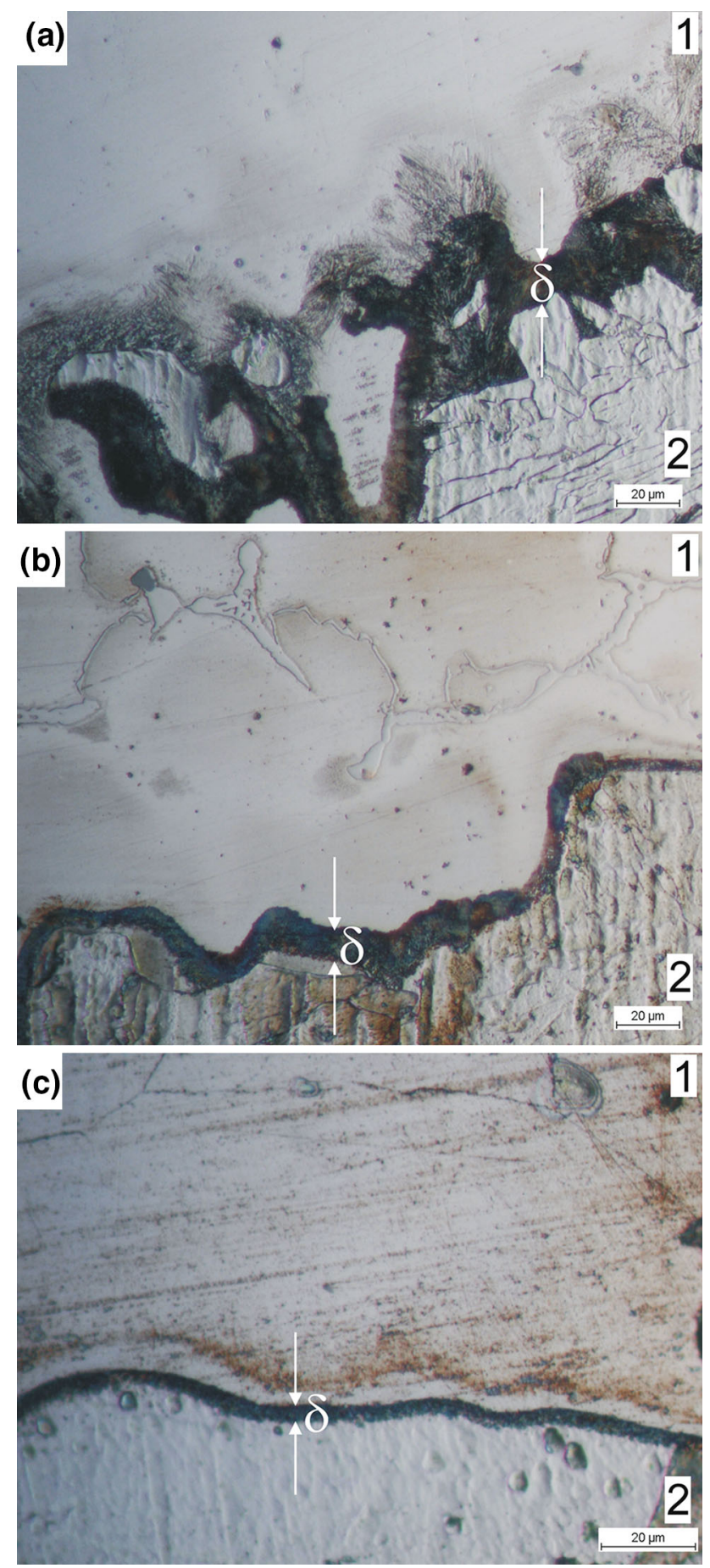

Fig. 6 Microstructure of the joint area between austenitic alloy steel (1) and ferritic-pearlitic unalloyed cast steel (2) at a pouring temperature of $1650^{\circ} \mathrm{C}$ and: (a) $\mathrm{C}=0.60 \mathrm{wt} . \%$, (b) $\mathrm{C}=0.43$ wt. $\%$, and (c) $\mathrm{C}=0.20$ wt. $\%$, LOM, etching Mi19Fe

2. The decisive phenomena needed to create a permanent joint between two components of the bimetallic casting are carbon and heat transport in the direction of high-carbon and hot material of the base part, which is poured into the mold in the form of liquid metal to a low-carbon and cold material of the working layer, which is placed in the mold cavity in the form of a monolithic insert.

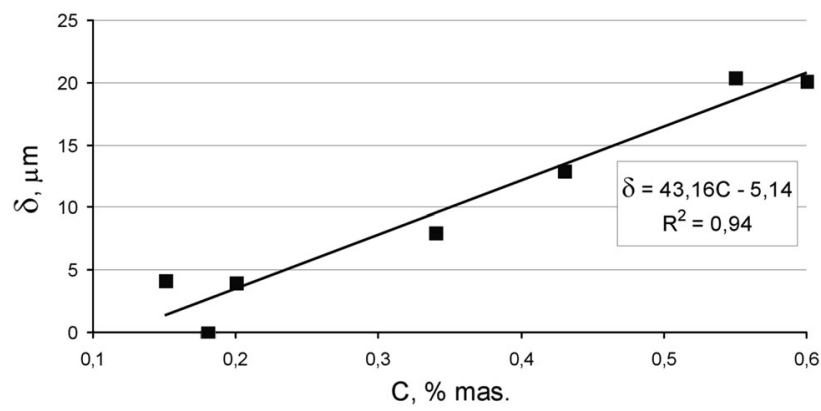

Fig. 7 Influence of the carbon concentration in unalloyed cast steel on the thickness of the pearlitic transition zone $(\delta)$ in a bimetallic casting at a pouring temperature of $1650{ }^{\circ} \mathrm{C}$

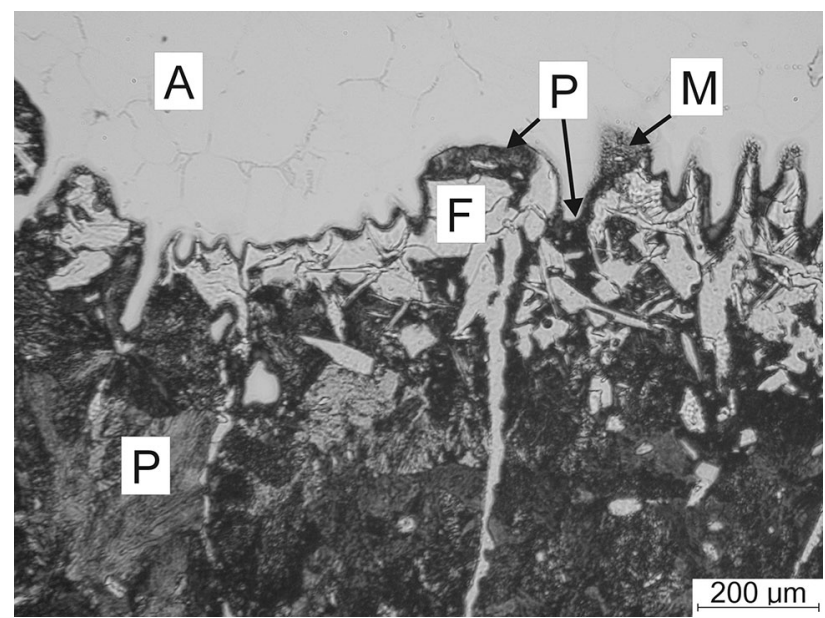

Fig. 8 Microstructure containing an increased amount of ferrite in the decarbonising boundary area of unalloyed cast steel: A austenite, $\mathrm{F}$ ferrite, $\mathrm{M}$ martensite, and $\mathrm{P}$ pearlite, LOM, etching A2

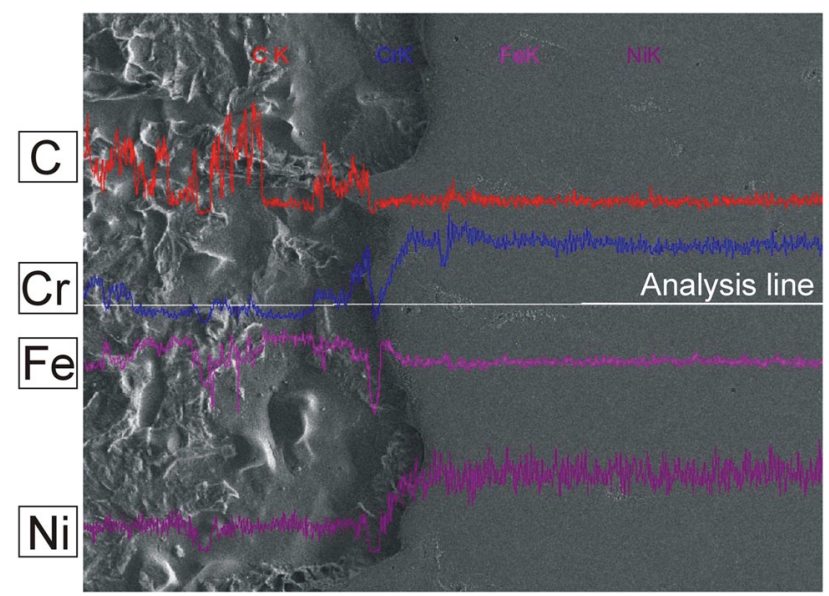

Fig. 9 Linear distribution of $\mathrm{C}, \mathrm{Cr}, \mathrm{Fe}$, and $\mathrm{Ni}$ in the joint area between ferritic-pearlitic unalloyed cast steel (on the left) and austenitic alloy steel (on the right)

3. As a result of carbon and heat transport transition zones were created in the microstructure of the bimetallic casting which contained on the side of the unalloyed cast steel an increased amount of ferrite and on the side of 

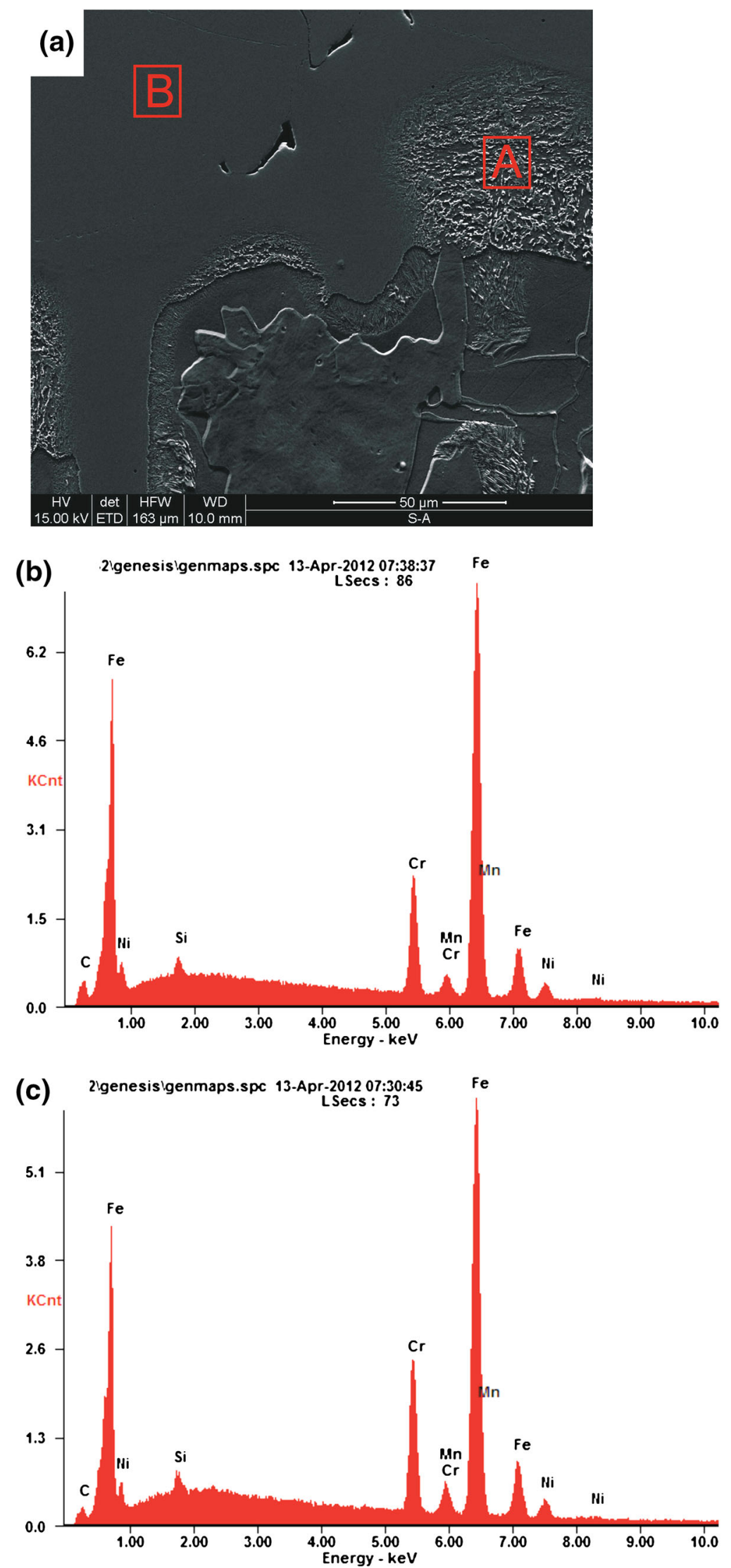

Fig. 10 Microanalysis of the chemical composition: (a) microstructure of the studied area, (b) the result in point A, (c) the result in point B 

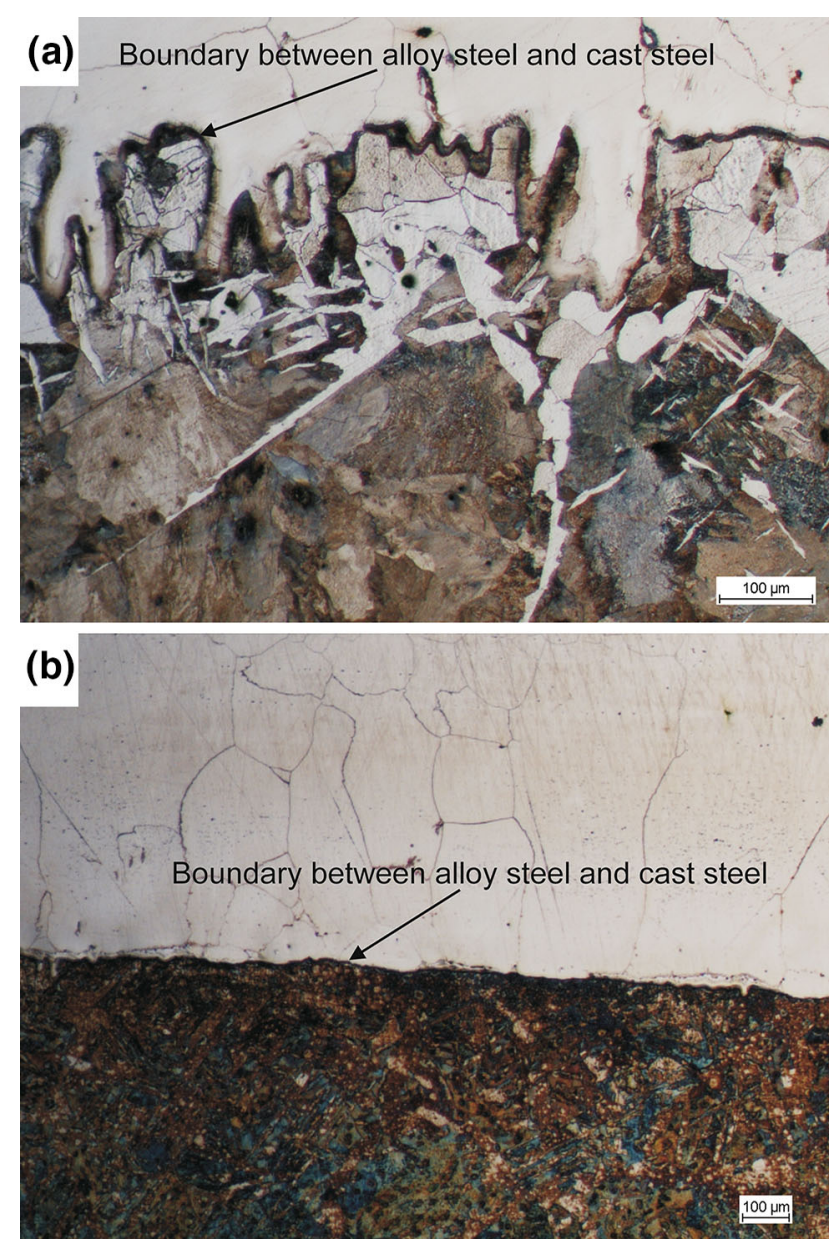

Fig. 11 Microstructure of the joint area between austenitic alloy steel (upper part) and ferritic-pearlitic unalloyed cast steel (bottom part) at a carbon concentration equal to $0.55 \mathrm{wt} . \%$ and: (a) $T_{\text {zal }}=1650{ }^{\circ} \mathrm{C}$, (b) $T_{\text {zal }}=1600{ }^{\circ} \mathrm{C}$

the chromium-nickel alloy steel some amount of martensite. The decarbonising zone of the base part with the carbonizing zone of the working layer joins the pearlitic zone at a thickness of tens of micrometers.

\section{Open Access}

This article is distributed under the terms of the Creative Commons Attribution License which permits any use, distribution, and reproduction in any medium, provided the original author(s) and the source are credited.

\section{References}

1. S. Žic, I. Džambas, and M. Konić, Possibilities of Implementing Bimetallic Hammer Castings in Crushing Industries, Metalurgija, 2009, 48(1), p 51-54

2. X. Xiaofeng, Y. Shengping, Z. Xiaoguang, and X. Qiong, High Cr White Cast Iron/Carbon Steel Bimetal Liner by Lost Foam Casting with Liquid-liquid Composite Process, China Foundry, 2012, 9(2), p 136-142

3. E. Marukovich, A. Branovitsky, Y. Na, J. Lee, and K. Choi, Study on the Possibility of Continuous-Casting of Bimetallic Components in Condition of Direct Connection of Metals in a Liquid State, Mater. Des., 2006, 27(10), p 1016-1026

4. T. Heijkoop and I. Sare, Cast-Bonding - A New Process for Manufacturing Composite Wear Products, Cast Metals, 1989, 2(3), p 160-168

5. J. Gawroński, J. Szajnar, and P. Wróbel, Study on Theoretical Bases of Receiving Composite Alloy Layers on Surface of Cast Steel Castings, J. Mater. Process. Technol., 2004, 157-158, p 679-682

6. J. Szajnar, P. Wróbel, and T. Wróbel, Model Castings with Composite Surface Layer-Application, Arch. Foundry Eng., 2008, 8(SI3), p 105-110

7. T. Wróbel, $\mathrm{Ni}$ and $\mathrm{Cr}$ Base Layers in Bimetallic Castings, METAL 2011: 20th Anniversary International Conference on Metallurgy and Materials, May 18-20, 2011 (Brno, Czech Republic), Tanger, 2011, p. 758-764

8. S. Jura and J. Suchoń, Odlewy warstwowe stal żeliwo (Layered Castings Sort Steel Cast Iron), Solidif. Metals Alloys, 1995, 24, p 67-70 (in Polish)

9. M. Qian, S. Harada, Y. Kuroshima, and H. Nagayoshi, Surface Hardening of Ductile Cast Iron Using Stainless Steel, Mater. Sci. Eng., $A$, 1996, A208, p 88-92

10. B. Arnold, T. Heijkoop, P. Lloyd, G. Rubens, and I. Sare, Wear of CastBonded Components in a Coal Pulveriser Mill, Wear, 1997, 203-204, p 663-670

11. D. Bartocha, J. Suchoń, and S. Jura, Odlewy warstwowe (Layered Castings), Solidif Metals Alloys, 1995, 38, p 151-156 (in Polish)

12. M. Şimşir, L. Kumruoğlu, and A. Özer, An Investigation into StainlessSteel/Structural-Alloy-Steel Bimetal, Mater. Des., 2009, 30(2), p 264-270

13. C. Cingi, V. Rauta, E. Niani, and J. Orkas, Cast Bonding of Cast Irons to Ferritic Stainless Steel, Mater. Sci. Forum, 2010, 654-656, p 2712-2715

14. B. Xiong, C. Cai, and B. Lu, Effect of Volume Ratio of Liquid to Solid on the Interfacial Microstructure and Mechanical Properties of High Chromium Cast Iron and Medium Carbon Steel Bimetal, J. Alloy. Compd., 2011, 509(23), p 6700-6704

15. B. Xiong, C. Cai, H. Wan, and B. Lu, Fabrication of High Chromium Cast Iron and Medium Carbon Steel Bimetal by Liquid-Solid Casting in Electromagnetic Field, Mater. Des., 2011, 32(5), p 2978-2982

16. J. Viala, M. Peronnet, F. Barbeau, F. Bosselet, and J. Bouix, Interface Chemistry in Aluminium Alloy Castings Reinforced with Iron Base Inserts, Composites A, 2002, 33(10), p 1417-1420

17. T. Lucey, R. Wuhrer, K. Moran, M. Reid, P. Huggett, and M. Cortie, Interfacial Reactions in White Iron/Steel Composites, J. Mater. Process. Technol., 2012, 212(11), p 2349-2357

18. M. Cholewa, T. Wróbel, S. Tenerowicz, and T. Szuter, Diffusion Phenomena Between Alloy Steel and Gray Cast Iron in Layered Bimetallic Casting, Arch. Metall. Mater., 2010, 55(3), p 771-777

19. www.struers.com. Accessed 28 Oct 2013

20. T. Wróbel, M. Cholewa, and S. Tenerowicz, Bimetallic Layered Castings Alloy Steel—Carbon Cast Steel, Arch. Foundry Eng., 2011, 11(1), p 105-107

21. P. Duda and J. Taler, Solving Direct and Inverse Heat Conduction Problems, Springer-Verlag, Berlin, 2006 